\title{
EL PROCESO DE FINANCIERIZACIÓN DE LA BANCA PÚBLICA COSTARRICENSE: EL CASO DEL BANCO NACIONAL, 1995-20051
}

\section{FINANCIALIZATION PROCESS OF COSTA RICAN PUBLIC BANKING: THE CASE OF THE NATIONAL BANK, 1995-2005}

\section{Daniel Cerdas Sandí*}

RESUMEN

\begin{abstract}
La reforma a la estructura socioeconómica que se vivió en Costa Rica desde la década de 1980, implica necesariamente cambios en el sistema financiero-bancario. Estos cambios conllevaron la finalización del monopsonio que ostentaba la banca estatal sobre los depósitos del público en 1995, modificando sustancialmente el accionar de la banca estatal. En el presente artículo se demuestra cómo se expresaron estos cambios en el Banco Nacional de Costa Rica (BNCR).
\end{abstract}

PALABRAS CLAVE: COSTA RICA * BANCOS * ADMINISTRACIÓN FINANCIERA * REFORMA ESTRUCTURAL * RÉGIMEN DE ACUMULACIÓN

\section{ABSTRACT}

The reform to the socioeconomic structure that Costa Rica experienced since the 1980s, necessarily implies changes in the banking and financial system. These changes have brought to the end of the monopsony who held the state bank on public deposits in 1995; this will substantially modified the actions of the state bank. In this article we show how these changes were expressed in the National Bank of Costa Rica (BNCR).

KEYWORDS: COSTA RICA * BANKS * FINANCIAL ADMINISTRATION * STRUCTURAL REFORM * ACCUMULATION REGIME

$1 \quad$ Este artículo muestra los principales resultados de la tesis de investigación del autor en la Maestría Centroamérica en Sociología de la Universidad de Costa Rica.

* Facultad Latinoamericana de Ciencias Sociales, México danielcerdas_3@yahoo.com 


\section{INTRODUCCIÓN}

La Teoría de la Regulación (Aglietta, Boyer, Bustelo, Jessop, Lipietz, principalmente) brinda da herramientas importantes para analizar los cambios que se dan en las estructuras socioeconómicas. El análisis a partir de dicha teoría es inclusivo e integral, no se enfoca en hechos aislados que no tengan relación con todo el sistema social capitalista y mucho menos se puede tratar de ver como hechos estáticos, sino más bien como un proceso dinámico en constante adaptación, con lo cual "no puede entenderse adecuadamente sin considerar la forma en que los modos de regulación modifican $y$ sin embargo permanecen sujetos a las leyes generales de la acumulación de capital" (Jessop 1999, 25).

Teniendo como base esta teoría, pero acercándola a la realidad costarricense, se analizan los cambios que se dieron en el sector financiero-bancario en el marco de los Ajustes Estructurales que se llevaron adelante en Costa Rica, con especial énfasis en las consecuencias sobre un banco estatal: el Banco Nacional de Costa Rica, después de 1995, cuando se rompe finalmente el monopsonio que tenía la banca pública sobre los depósitos del público.

Además de la Teoría de la Regulación, se utiliza la propuesta de David Harvey para explicar los procesos de financierización de las economías que se vienen dando con el auge del neoliberalismo. Costa Rica no escapa de dicho proceso $y$ es a fin de cuentas lo que experimenta la banca pública. El caso del Banco Nacional que se expone en este artículo es un reflejo de este proceso de financierización.

Sobre la metodología utilizada se debe señalar que la investigación es un estudio descriptivo-relacional y temporalmente sincrónico. El espacio temporal del estudio abarca de 1995 a 2005. El alcance territorial de la investigación fue nacional, sin dejar de lado las influencias del contexto internacional. Se hizo uso de métodos de investigación, como el comparativo (para contrastar períodos: 19501980/1980-1995/1995-2005), el método cualitativo, el método histórico y el estudio de caso. La investigación privilegió la técnica de análisis de contenido para describir tendencias y develar semejanzas o diferencias en el contenido de los documentos, así como identificar grupos o sectores específicos con intereses comunes. Además, se procedió al uso de entrevistas analíticas a funcionarios, utilizando la técnica de la entrevista enfocada, es decir, un tipo de entrevista a profundidad, que enfatizó un único núcleo o foco de interés, ya que se pretendía dar respuesta a asuntos muy concretos.

\section{TEORÍA DE LA REGULACIÓN E INSTITUCIONES FINANCIERAS}

Un régimen de acumulación debe entenderse como el sistema que permite la apropiación del excedente de riqueza, producto de la fuerza de trabajo de las mayorías trabajadoras, por parte de sectores hegemónicos de la sociedad (Mandel 1969). Además, Bustelo indica que "por régimen de acumulación se entiende el modo de transformación conjunta y compatible de las normas de producción, de distribución $y$ de uso" (2003, 147). Además, agrega que este régimen "permite durante un período largo, adecuar las transformaciones de las condiciones de producción y los cambios en las condiciones de consumo" (Bustelo 2003, 147).

Esta noción plantea que la economía tiene un claro carácter institucional que pretende darle coherencia al esquema de reproducción; con lo que el proceder de los diferentes actores existentes dentro de la sociedad sea compatible con el régimen de acumulación. A esto se le llama modo de regulación, es decir, "se entiende el conjunto de normas, implícitas o explícitas, de mecanismos de compensación, de dispositivos de información, que ajustan permanentemente las expectativas y los comportamientos individuales a la lógica de conjunto del régimen de acumulación" (Bustelo 2003, 147). Sobre estas normas, sobresale la forma de determinación de los salarios, tipo de competencia entre empresas y la forma en que se gestiona la política monetaria. Se debe señalar que "la estabilidad o reproducción duradera de un régimen de acumulación depende de su articulación con un determinado modo de regulación" (Ídem).

Bob Jessop y Ngai-Ling Sum (2006), haciendo una revisión de la Teoría de la Regulación, analizan el paso de las sociedades 
industrializadas del fordismo al postfordismo ${ }^{2}$. Realizando algunas adecuaciones, el estudio aquí presentado analiza los cambios en el régimen de acumulación y el modo de regulación que suceden en Costa Rica desde la década de 1980. No se detendrá a analizar las características de las propuestas de Jessop para el análisis del fordismo y postfordismo industrial, sino que se concentrará en el caso costarricense ${ }^{3}$.

El régimen de acumulación y el modo de regulación que se empieza a configurar en Costa Rica en el periodo que va de 1980 en adelante, se ha llamado "Aperturismo Globalizado", siguiendo la propuesta de Reuben (2009), el mismo hace referencia a dos rasgos de ineludible mención que caracterizan al país desde entonces y que se ha acentuado en los últimos años con la firma de tratados de libre comercio (TLC).

Los programas de ajustes estructurales aplicados (PAE-I en 1985, PAE-II en 1989 y PAEIII en 1995), más las políticas relacionadas o en consonancia con los mismos durante las dos últimas décadas del siglo $\mathrm{xx}$, ocasionaron importantes cambios en la estructura socio-económica de Costa Rica, en especial en el sector productivo, lo cual implicaba también cambios en el sistema financiero-bancario.

$2 \quad$ Para una lectura detallada de los niveles de análisis en el fordismo y el postfordismo puede consultarse: Jessop, 1999 y Jessop y Sum, 2006.

3 La Teoría de la Regulación es concebida para entender las sociedades industriales, tanto en el fordismo como en la superación de este. Si bien, se habla de determinados regímenes de acumulación y modos de regulación en Costa Rica, no se puede asimilar a los vividos en el mundo desarrollado, pues mientras se habla de fordismo en Estados Unidos o Europa, en Costa Rica no sucede lo mismo, puesto que en un caso se trata de las regulaciones que se dan en el marco del auge de grandes empresas industriales, mientras que en Costa Rica se trataba más de lograr regulaciones que permitieran alcanzar la industrialización. Es necesario aclarar que para el caso de análisis en Costa Rica, se ha periodizado las regulaciones en: "desarrollismo" para el periodo que va de 1950 a 1980 (se pretende desarrollar en capitalismo en el país) y "aperturismo globalizado" para el periodo que se da de 1980 en adelante (se pretende mediante la apertura de mercado globalizar la economía nacional). Para ver con detalle las características de estos períodos puede consultarse: Cerdas, 2013.
Tal como lo menciona Reuben (1988), los principales ejes en que se fundamenta el nuevo régimen de acumulación y el modo de regulación son tres ${ }^{4}$ :

1. La política de estímulo a las exportaciones e importaciones.

2. La reforma al sistema financiero y bancario.

3. La reducción de la intervención estatal en diversas áreas no solo económicas, sino también sociales.

Pero este proceso de cambios sustanciales en toda la estructura nacional (social, económica, agrícola, cultural, etc.), no debe verse como un hecho aislado que atañe solo a Costa Rica, sino que debe de contextualizarse a los cambios globales, es decir, a la crisis del sistema capitalista mundial en su forma fordista. El modo de regulación fordista "constituía un fardo pesado para la natural necesidad del sistema de generar, competitivamente, mayores ganancias con sus capitales invertidos" (Reuben 2009,138), de ahí la necesidad del capital de buscar una nueva forma de valorarse y regularse que le permitiera obtener mayores tasas de ganancia.

Poco a poco "se va constituyendo un nuevo consenso entre distintos sectores de las burguesías nacionales, sobre la necesidad de transformar la estructura de regulación del régimen de acumulación dominante" (Reuben 2008, 80), la reestructuración y la internacionalización de la producción auguraba considerables aumentos en las tasas de ganancia. Esto condujo a la revisión del Estado de Bienestar $-y$ sus políticas públicas - del mundo desarrollado y se buscó modificar las bases del modelo fordista (Reuben 2008), con lo que también el modelo desarrollista costarricense debía ajustarse a los nuevos intereses económicos, pues se crea un ambiente de negocios internacionales favorecido por la desterritorialización de las empresas transnacionales, su flexibilidad $y$ la ampliación del comercio y el transporte internacional, donde la propuesta desarrollista de

$4 \quad$ Autores como el sociólogo Jorge Rovira agregan también un cuarto pilar: la reforma laboral (Rovira 2004), el cual por cuestiones de limitación de la presente investigación no se abordarán. 
impulsar soberanamente su mercado interno no tiene cabida.

Esta búsqueda —en los países desarrollados- de mecanismos que permitan invertir nuevamente el capital, con tasas de ganancias superiores a las que les ofrecía el sistema fordista, se convirtió en una necesidad. Las medidas adoptadas para alcanzar esto son: "a) desplazamientos temporales mediante la inversión en proyectos a largo plazo o gasto social...b) desplazamientos espaciales mediante la apertura de nuevos mercados, nuevas capacidades de producción y nuevas posibilidades en otros lugares o c) alguna combinación de a y b" (Harvey 2004, 93).

En estas opciones de maniobra, el papel del sector financiero es decisivo, pues: “...todo esto depende del papel mediador crucial de las instituciones financieras $y / 0$ públicas para canalizar los flujos de capital entre los tres circuitos mencionados [producción y consumo de bienes inmediatos, capital fijo y formación de fondos de consumo $y$ gasto social e investigación y desarrollo]" (Ibíd., 96).

Es decir, que las instituciones financieras ostentan un rol central al determinar qué sectores de la economía se fomentan; para el caso de Costa Rica la apertura de nuevos mercados, nuevas capacidades de producción y nuevas posibilidades en otros lugares son reflejo de esto ${ }^{5}$. En palabras de Harvey: "La forma que asumen las instituciones mediadoras es la de productoras, a la vez que producto, de la dinámica de la acumulación de capital" (Harvey 2004, 108).

Es por esto que las reformas al sistema fordista incluyeron como eje determinante cambios al sistema financiero internacional.

En consecuencia, el sistema bancario y financiero costarricense $y$ por ende, el Banco Nacional, como institución financiera, mantienen un papel determinante en el proceso de acumulación de capital, en cuanto son determinantes en los flujos de capital para la inversión y la obtención de ganancias. Pero el capital financiero comprende también una gran cantidad de actividad especulativa (bolsas de valores, fondos de pensión, de inversión, etc.) en la que el dinero

$5 \quad$ El trabajo de Antonio Luis Hidalgo da muestra de esto: Hidalgo, 2003. se usa sencillamente para acumular capital mediante la especulación en mercancías futuras, valores monetarios, deuda y demás. Cuando se dispone de grandes cantidades de capital para estos fines, los mercados abiertos de capital se vuelven vehículos para la actividad especulativa (Harvey 2004). Además, el Estado también influye a través del Banco Central, órganos de supervisión y nuevas leyes, estableciendo el marco regulatorio para todo el sector bancario y financiero, regulaciones reformadas en consonancia con lo que dictaban los organismos financieros internacionales a inicios de la década de 1980.

Estas reformas que se dan en el plano internacional y nacional son parte del proceso de financierización. Se entiende la financierización como la realización de un verdadero sistema global para la obtención de recursos, en tiempo real y en el lugar del planeta que las necesidades del capital mundial dictaminen. Como señala Reuben (2008), es crear las condiciones para que la acumulación de capital pueda darse con facilidades más allá de las fronteras de cada país; se recuerda que la crisis del fordismo, entre otras cosas incluye "las limitaciones relativas del tamaño del mercado nacional y la rigidez implícita de un proceso de acumulación de capital a escala nacional. La dimensión de la acumulación de capital a escala global asume pues, ahora, un carácter real, concreto, virtualmente inmediato" (Reuben 2008, 81).

La nueva estructuración del capitalismo mundial lleva a que "cada país, cada nación, cada pueblo que se autogobierna [...], constituye un régimen de acumulación que hace coherente la articulación interior de sus estructuras de acumulación y de regulación con el entorno integrado internacionalmente" (Reuben 2008, 76).

Es decir, la configuración de un nuevo régimen de acumulación, viene de la mano con la tendencia mundial de búsqueda de nuevos espacios de inversión, que permitan colocar los excedentes de capital ocioso. De esta manera, el proceso de financierización se hace en razón de estos nuevos espacios. Esto es posible, mediante el papel esencial que cumple la banca como catalizador de capitales en espacios determinados de inversiones. Por lo tanto, las reformas al sistema financiero nacional están planeadas 
para garantizar la acumulación de capital $-y$ conectarlas con las redes de valorización internacional-, de clases o fracciones de clases dominantes, encubiertas en discursos que apelan al interés general, aunque en la realidad estén muy lejos de eso.

No se puede dejar de lado que el proceso de financierización, al definir una nueva regulación, implicó también que surgiera una poderosa ola financiera que comenzó después de 1980 y que ha estado marcada por su estilo especulativo y predatorio (Sevares 2005). Así, la desregulación (nueva regulación) que se dio en gran parte del mundo, permitió que el sistema financiero se convirtiera en uno de los centros principales de actividad de redistribución mediante la especulación. El énfasis en los mercados de valores, condujo, como se sabe ahora, a manipulaciones en el mercado que crearon inmensa riqueza para unos pocos a costa de los muchos. También se debe considerar los robos especulativos realizados por fondos de alto riesgo $y$ otros importantes instrumentos del capital financiero que formaron la verdadera vanguardia de la acumulación por desposeimiento, incluso aunque supuestamente conferían el beneficio positivo para la clase capitalista de "repartir los riesgos" (Harvey 2007).

\section{CAMBIOS EN LA REGULACIÓN BANCARIA}

La primera reforma a favor de la banca privada se encuentra en 1972 cuando se abre la posibilidad al sector privado de captar ciertos depósitos del público. La reforma de 1978 al Sistema Bancario Nacional, era una respuesta a la crisis del régimen de acumulación desarrollista $y$ sus consecuencias se encaminaban hacia las grandes reformas que enfrentaría el sistema años después.

La estructura del sistema financierobancario que se configuró en el periodo desarrollista, basada principalmente en una banca nacionalizada, tuvo como principal objetivo encaminar al país hacia la industrialización y el desarrollo de la acumulación nacional de capital. Los sectores más beneficiados de ese sistema fueron la agricultura, la ganadería y la industria.
De esta manera, el Sistema Bancario Nacional de 1950 a 1980, era congruente con el régimen de acumulación y su modo de regulación desarrollista, donde el Estado jugó un papel central como interventor de todos los espacios de la vida social, no solo económica. El periodo desarrollista costarricense se caracterizó por centrarse en el crecimiento del mercado interno, industrializar la economía nacional, seguir los lineamientos de la Comisión Económica para América Latina y el Caribe (CEPAL) en relación al "crecimiento hacia adentro" (sustituir importaciones) y fomento al pequeño productor agropecuario.

Como se ha señalado, a inicios de la década de 1980 (y en adelante), se aprobaran en el país reformas estructurales y leyes conexas que tienen como principal objetivo reconfigurar el régimen de acumulación y su modo de regulación desarrollista, ante lo cual la banca nacionalizada $y$ todo el sistema financiero-bancario nacional no se escaparon ${ }^{6}$. Los cambios se orientaron hacia la apertura comercial, la atracción de empresas transnacionales, el fomento a la economía vinculada al sector externo, la apertura del mercado financiero, la disminución del Estado y la separación del Estado de las actividades económicas.

El paso del desarrollismo al aperturismo globalizado, como régimen de acumulación en Costa Rica, está en total alineamiento con los requerimientos del capital transnacional. En la tabla 1 se puede ver de manera comparativa las principales características que se presentan en cada periodo analizado (1950-1980 vs 1980-2010) del sistema financiero-bancario costarricense.

$6 \quad$ Se está hablando de los Programas de Ajuste Estructural (PAE-I, PAE-II y PAE-III). Pero además de estos, sería necesario una serie de leyes adicionales que ajustaran finalmente, el Sistema Bancario Nacional a un nuevo régimen de acumulación. Estas leyes serían: Reforma Financiera de 1978, Ley de Modernización Financiera (nro. 7107) de 1988, Ley Reguladora del Mercado de Valores (nro. 7201) de 1990, Ley de Régimen Privado de Pensiones Complementarias (nro. 7253) de 1995, Reforma a la Ley Orgánica del Banco Central de Costa Rica (nro. 7558) de 1995 y Ley Reguladora del Mercado de Valores (nro. 7732) de 1997. Para un mayor detalle de este proceso puede consultarse: Cerdas, 2013: 72-102. 
TABLA 1

RESUMEN COMPARATIVO DE LAS REGULACIONES

BANCARIO-FINANCIERAS DE LOS PERIODOS DESARROLLISTA Y APERTURISTA GLOBALIZADO

\begin{tabular}{|c|c|}
\hline DESARROLLISMO & APERTURISTA GLOBALIZADO \\
\hline Banca estatal (solo estos captan recursos del público). & $\begin{array}{l}\text { Banca mixta (estatal y privada pueden captar recursos } \\
\text { del público). }\end{array}$ \\
\hline $\begin{array}{l}\text { Sistema bancario con fines de una acumulación } \\
\text { nacional de capital sociales. }\end{array}$ & $\begin{array}{l}\text { Sistema bancario únicamente con fines de acumulación } \\
\text { de capital desterritorializado. }\end{array}$ \\
\hline $\begin{array}{l}\text { Banco Central sujeto al proyecto político del Poder } \\
\text { Ejecutivo. }\end{array}$ & $\begin{array}{l}\text { Banco Central con mayor autonomía y mayores } \\
\text { poderes. }\end{array}$ \\
\hline Estructura rígida del tipo de cambio. & Estructura flexible de tipo de cambio. \\
\hline $\begin{array}{l}\text { Tope para carteras de crédito (se estimulan sectores } \\
\text { productivos del mercado interno). }\end{array}$ & Las carteras de crédito las define el mercado. \\
\hline $\begin{array}{l}\text { Tasas de intereses reguladas y definidas políticamente } \\
\text { (incentivo a sectores). }\end{array}$ & Tasas de intereses definidas por el mercado. \\
\hline $\begin{array}{l}\text { Fomento especial a la producción de alimentos, } \\
\text { ganadería e industria. }\end{array}$ & $\begin{array}{l}\text { No hay fomentos específicos a sectores, el mercado } \\
\text { define esto, pero se aplica una política económica y } \\
\text { fiscal que favorece la competitividad de los sectores } \\
\text { exportadores. }\end{array}$ \\
\hline $\begin{array}{l}\text { Otorgamiento de subsidios a determinados sectores } \\
\text { productivos. }\end{array}$ & Subsidios fiscales a los sectores exportadores. \\
\hline Fomento especial a zonas rurales. & Desaparición de Juntas Rurales de Crédito. \\
\hline Existencia de Juntas Rurales de Crédito. & $\begin{array}{l}\text { Desarrollo de nuevos mercados financieros, nuevos } \\
\text { productos e instrumentos financieros, etc. (proceso de } \\
\text { financierización). }\end{array}$ \\
\hline $\begin{array}{l}\text { Banca tradicional enfocada en el otorgamiento de } \\
\text { créditos, no de mercados de capitales, especulación } \\
\text { financiera, etc. }\end{array}$ & $\begin{array}{l}\text { Se crean órganos de regulación de pensiones (SUPEN) y } \\
\text { de mercado de valores (SUGEVAL). }\end{array}$ \\
\hline Existencia de AGEF con esquema represivo ex post. & $\begin{array}{l}\text { Se crea SUGEF con esquema de supervisión prudencial } \\
\text { ex ante. }\end{array}$ \\
\hline
\end{tabular}

Fuente: Cerdas, 2013.

El Ministerio de Planificación y Política Económica abiertamente señalaba la necesidad de cambiar el sistema financiero-bancario para los intereses de una economía globalizada:

Las transformaciones que está experimentando la economía costarricense tienen como propósito integrarla gradualmente, tanto financiera como comercialmente al campo internacional. Es decir, pasar de un modelo de crecimiento hacia adentro a un modelo de crecimiento hacia afuera. En este proceso el sistema financiero ha experimen- tado cambios específicos los cuales han operado en dos sentidos: la liberalización financiera interna $y$ la apertura financiera externa (Ministerio de Planificación Nacional y Política Económica de Costa Rica-midEPLAN 1993, 5).

Como se analizará posteriormente, estos cambios que se han mostrado tendrán importantes impactos en el accionar del Banco Nacional (BNCR). El Bscr dejó de lado su vocación hacia sectores de la economía productiva nacional como la agricultura o la industria y se avocó por los designios del mercado: más rentabilidad y menos riegos. 
PRINCIPALES IMPACTOS EN EL BANCO NACIONAL DE COSTA RICA

El Banco Nacional tuvo una reacción lenta a los cambios que implicaba la apertura del mercado financiero (1995), pues su reestructuración (en su accionar y estructura) se dio hasta cuatro años después. A razón de los cambios que implicaba la reforma de 1995, la Junta Directiva del Banco Nacional reaccionó contratando un nuevo gerente general, proveniente de la empresa privada ${ }^{7}$. El nuevo Gerente General, Lic. William Hayden, dejó claro desde un inicio que una de sus metas sería modificar los objetivos del banco de "motivación al desarrollo y no al lucro por el de motivación al lucro en la financiación al desarrollo" (BNCR 1998, 6).

El Plan Estratégico 99-03 (РE 99-03) propuesto en la nueva gerencia mostró de inmediato un marcado interés por vincularse con el sector empresarial transnacional, así como, el de incurrir en nuevos sectores financieros que tienen que ver más con la especulación que con la economía real. Se denota la intención de realizar un cambio profundo en el enfoque que hasta entonces había tenido el Banco Nacional. Incluso no hay un interés de defender la banca estatal, a tal punto que muestra como una oportunidad la privatización de las otras instituciones bancarias públicas con tal de obtener esas cuotas de mercado.

En la nueva visión que el BNcr asume, deja de ser únicamente un banco de operaciones locales y se define como una institución que participa de la economía mundial, se suma a esto la omisión de sectores que anteriormente eran mercados meta del banco: el micro, pequeño y mediano productor nacional, en su lugar se habla ahora de segmento masivo y corporativo, entendido el primero como todos aquellos clientes que llegan a hacer uso de sus productos $y$ servicios, $y$ el segundo como las grandes empresas que necesitan de un banco para llevar adelante sus negocios.

$7 \quad$ Es significativa esta recomendación de contratar un gerente general proveniente del sector privado, pues hasta entonces había sido una práctica usual que dicho cargo fuera ocupado por un funcionario de larga trayectoria dentro de la institución.
El PE 99-03 era todo un plan de reestructuración del BNCR con el claro propósito de lograr que este se asumiera en el nuevo modo de regulación y régimen de acumulación aperturista globalizado. El PE 99-03 no buscó debilitar o disminuir al BNcR, buscó hacerlo funcional al nuevo régimen de acumulación. Por tanto, aunque no se viva un proceso de privatización y de otorgar mercado a la banca privada, la reestructuración del BNcR sí está acorde con los ajustes estructurales y esto se ve en los resultados que presenta el Banco en los años siguientes.

Los principales cambios que se observan son a nivel de utilidades. La institución históricamente estuvo enfocada en dar un servicio para el desarrollo de las fuerzas productivas del país con lo que su interés no había sido generar ganancias como meta principal, hasta el proceso de financierización. Por otra parte, la composición de la cartera crediticia tuvo cambios significativos al perder participación los créditos destinados a la industria, agricultura y ganadería, mientras que hay un notorio ascenso de los rubros consumo, vivienda y comercio.

Lo primero que resalta al analizar los cambios en el tiempo de la cartera de crédito es el considerable aumento que representan los recursos destinados al sector vivienda, mientras en 1995 representaba el 5,52\% (\$3360,10 millones), para el año 2000 alcanzó 28,47\% (\$64 132,40 millones) y para el año 2005, el mismo rubro llegó a 37,18\% (\$261 000,00 millones) lo que lo convierte en el sector que más recursos recibió del Banco.

Por su parte, el sector comercio presentó una tendencia creciente, no de igual forma que la vivienda pero sí muestra con el paso del tiempo incrementó en su participación. Este sector en el año 1995 recibió $\$ 7601,50$ millones representando el $12,49 \%$ del total de la cartera, para el año 2000 la cifra se ubicaría en $\$ 42415,10$ millones (15,18\%) y finalmente, en el año 2005 se dejaría $\$ 81500,00$ millones representando el $15,12 \%$. Otro sector que presenta un crecimiento importante es la construcción, el cual en 1995 no llegaba ni al uno por ciento $(0,55 \%)$, para el año 2000 lograría recibir $\$ 3752,50$ millones lo que representaría un $1,39 \%$ y para el 
año 2005 llegaría a obtener un 2,71\% al percibir $\$ 19$ 000,00 millones.

El sector agricultura es uno de los que tendrá un comportamiento a la baja muy marcado, en el año de 1995 recibió \$13 233,60 millones, lo que significó el $21,75 \%$ de la cartera crediticia del BNcR, para el año 2000 el porcentaje llegó a 12,77\% (\$35 681,40 millones) y en el año 2005 recibió $\$ 33$ 000,00 millones representando el 4,84\%. De la misma forma la ganadería se vendría abajo, mientras que en el año 1995 representó el 8,64\% (\$5258,30 millones), para el año 2000 la cifra llegó al 4,29\% (\$11 972,30 millones) y para el año 2005, los datos llegaron a 2,88\% (\$19 000,00 millones). Se suma a los sectores en depresión la industria, pues en 1995 participó con el 15,48\% ( $\$ 9423,20$ millones), los datos para el año 2000 fueron de 13,47\% (\$37 630,80 millones), mientras que para el año 2005 la cifra llegó a $\$ 48$ 000,00 millones, representando el 6,84\%.

Las intenciones de ingresar a los mercados especulativos eran muy serias, Hayden indica:

...los fondos tienen un crecimiento espectacular a través de la banca que lanza productos muy imaginativos de acuerdo a las circunstancias del mercado: fondos de renta fija, fondos de renta variable, fondos garantizados que basan su seguridad en la cobertura mediante instrumentos derivados complejos, etc. (s.f., 106).

Con esto en mente, el 28 de mayo de 1999, se creó la sociedad BN-SFI Administradora de Fondos de Inversión. En abril de 1998, el Banco Nacional siguió su camino hacia la financierización e inscribió la sociedad anónima "BN-Valores. Puesto de Bolsa sA". El Banco tuvo una estrategia agresiva que lo llevó incluso a "fusionarse" con una empresa privada (Continental Valores) (Ibíd., 102-103).

Con la creación de las sociedades anónimas en las áreas de pensiones, banca de inversión y mercado de valores, sumado a la descentralización (creación de bancos regionales), el banco paso a tener una estructura de corporación. Esto conlleva una mayor participación del Banco en actividades diferentes al crédito y que acercaban a la institución al proceso de financierización.

Sumado a estas sociedades, el Banco también creó la Dirección Corporativa de Banca de Inversión con la que se pretendía procurar negocios e ingresos para la entidad no relacionados con la intermediación financiera, aprovechando que a través de ellas se iba a generar una serie de nuevos negocios derivados de las operaciones bursátiles, el manejo de fondos de pensiones y la administración de fondos de inversión (Hayden s.f.).

Como se indica, estos servicios son dirigidos a sectores corporativos, que tienen grandes posibilidades económicas para hacer negocios. Un ejemplo del mercado meta del Banco Nacional a través de esta banca de inversión, es el fondo que se creó en conjunto con la cadena hotelera, la transnacional Marriot por us $\$ 18,0$ millones para el financiamiento de la compra de villas en los condominios "Colina Los Sueños" y "Bella Vista Los Sueños", ambos dentro del complejo Marriot-Sueños (BNcR 2001).

Durante la gestión de William Hayden, la subsidiaria BICSA (banco offshore con oficinas en Panamá y Miami, en que los accionistas son los bancos del Estado costarricense) pasó a tener otra significación, pues se buscaba internacionalizar al BNcr creando sucursales en los países de Centroamérica y del Caribe. Históricamente, el BNcr había sido poseedor del 55\% de las acciones, pero con este proyecto se pretendía aumentar el porcentaje de participación y así el Banco Nacional buscó adquirir esta subsidiaria comprándole a los otros bancos el $45 \%$ restante de las acciones, de forma tal que la expansión regional en esta forma se haría a través de Bicsa (Hayden, s.f.). Finalmente, este proyecto no se logró por limitaciones legales.

En este periodo, las Juntas Rurales de Crédito (JRC) -que fueron elementos clave en las funciones del BNcR como institución del desarrollismo - van prácticamente a desaparecer. En 1999, el BNCR inició, paralelo a las JRc, el programa de fomento a la micro y pequeña empresa, desde su comienzo dirigió sus esfuerzos al sector industria, comercio y servicios, estos dos últimos con mayor participación (BNCR 2000). 
En el año 2000, el programa de micro y pequeña empresa se transformó en el Departamento de BN-Desarrollo, fusionando en este, las JRC (desapareciendo). El gran perdedor será el sector agrícola, mientras que el comercio y los servicios serán los sectores mejor posicionados en la distribución de estos recursos. Los datos reveladores de la distribución de la cartera de crédito, tanto cuando se observa la global, como cuando se acerca específicamente a $\mathrm{BN}$-Desarrollo, en los que sectores como industria, ganadería y especialmente agricultura, sufren una caída significativa, no solo responden a políticas propias del BNCR, sino que el sistema mismo de regulación exigía este comportamiento.

Las nuevas regulaciones le traerían problemas al BNCR, principalmente en el indicador de suficiencia patrimonial, en el año 2001, la institución enfrentaría una pequeña crisis y el sector agrícola sería uno de los perjudicados, el Periódico La Nación realizó un reportaje al respecto en el que se lee:

Hayden justificó que el banco es un conglomerado financiero en el que las subsidiarias generan utilidades cuando la actividad de intermediación (préstamo y captación de dinero) no es dinámica. Pero, para Hayden los problemas empeoraron cuando entraron en vigencia las normas 22, 23 y 24 de la sugef, las cuales modifican la forma de calificar a los bancos y les redujo su suficiencia patrimonial de $11,73 \%$ a $10,39 \%$.

El gerente citó como ejemplo el hecho de que ahora uno de los indicadores de calificación le exige al banco tener una cartera sana del 95\%, algo difícil cuando arrastra problemas con las carteras bananera $y$ cafetalera.

Brenes aseguró que estas normas son un obstáculo para la banca de desarrollo.

Por eso presentaron al Congreso un proyecto para que la sugef flexibilice los parámetros para medir ese tipo de créditos.
[...] El banco también empezará a incluir el factor de riesgo en las tasas de interés de cada actividad en la que preste dinero.

Hayden mencionó que solo en la agricultura el riesgo es de 2,89 puntos porcentuales, por lo que la tasa debería ser 2,89 puntos mayor a la actual.

Rodolfo Brenes y William Hayden, presidente $y$ gerente del Banco Nacional, admitieron que las normas son buenas, pues tratan de proteger el ahorro de los clientes. Pero se quejaron, pues el banco no puede ser medido como cualquier otro, ya que gran parte de sus créditos están dedicados a actividades agropecuarias, más riesgosas.

"El banco ya no se mide por su función social, ahora las reglas de juego se llaman patrimonio, capital y utilidades", señaló Hayden [...] (Delgado 13/08/2001) (Subrayado del autor).

En este escenario de cambios, el señor Alfredo Volio (Director de la Junta Directiva del BNcR y Presidente en varias ocasiones de la misma), en un artículo de opinión en el semanario El Financiero escribió:

El Banco Nacional forzosamente tiene que adaptarse a las nuevas reglas de juego. ¿Qué propician ellas? Capitalización y rentabilidad. Los bancos deben tener un capital suficiente para hacer frente a sus activos en riesgo. Si no tienen un fuerte capital (en comparación con el volumen de sus activos) deben entonces disminuir sus activos en riesgo (principalmente crédito) o, en su defecto, aumentar el capital. ¿Cómo se aumenta el capital? Con aportes de los socios o con utilidades. ¿Cómo se obtienen más utilidades? En el caso de los bancos, aumentando el margen financiero (mayores 
tasas de interés sobre los préstamos y menores tasas sobre los depósitos), mejorando la calidad de la cartera crediticia para no hacer fuertes reservas (lo cual implica no prestarle a sectores riesgosos como la agricultura, por ejemplo), mejorando los ingresos no asociados a la intermediación financiera $y$, finalmente $y$ no por ello menos importante, reduciendo el gasto.

[...] La adopción de estas medidas no implica, como lo está señalando alguna prensa poco profesional, los enemigos del Banco Nacional y ciertos bancos competidores, que el Banco Nacional está en crisis. Cambiaron las reglas de juego. Ahora privan las utilidades sobre la función social, $y$ la capitalización sobre los programas de desarrollo económico (Volio 01/09/2001) (Subrayado del autor).

Se puede observar claramente las consecuencias sobre la banca estatal de las reformas que se aplicaron a todo el sistema, tanto al leer las declaraciones de don William Hayden, como el artículo de don Afredo Volio: las reglas cambiaron y el Banco Nacional necesariamente tuvo que cambiar con ellas.

Es evidente que la meta del plan de reestructuración de generar la mayor cantidad de ganancias posible, fue básicamente el objetivo primordial, en palabras de William Hayden, cambiar su meta social por la meta del lucro y efectivamente, es un cambio muy notorio en este periodo analizado. Las ganancias en el año 1995 fueron de $\$ 151,75$ millones y para el año 2005 , la cifra alcanzó la suma de $\$ 35$ 008,90 millones, lo que representa un crecimiento en utilidades de un $23070,11 \%$ con relación a 1995, si incluyéramos el año 2006, en el cual se tuvo como ganancia $\$ 46200,00$ millones, el cambio porcentual sería de un $30444,81 \%$.

\section{CONCLUSIONES}

El BNCR experimentó un profundo cambio en todo su funcionamiento, la institución que se configuró a partir de 1950 dejó de ser tal a partir de 1997. Es la ley que rompe con el monopolio del mercado bancario por parte del Estado en 1995, la que causará tan significativas modificaciones en la entidad bancaria.

Este proceso de cambios en el sistema financiero-bancario se debatió entre debilitar la banca estatal o hacerla funcional a los nuevos intereses de los grupos de poder (mercados globales, fomento a mercados de capitales, fomento a neoexportaciones e importaciones), finalmente, esta segunda tesis se impuso logrando así crear una gran corporación bancaria que renunció a su misión histórica de promover el desarrollo productivo y lo cambió por la generación de ganancias.

En la Memoria Institucional de 1999, William Hayden en su Mensaje del Gerente General sin ningún miramiento expresa: "El Banco Nacional de Costa Rica inició en 1997 un proceso diferente de organización y administración que consistió en privatizar la mentalidad $y$ no la propiedad. La idea fue privatizar la organización, la administración, la forma de hacer negocios, $y$ buscar eficiencia, eficacia y rentabilidad, a fin de llegar a hacer del Banco nuevamente el número uno del sector financiero del país y en el corazón de todos los costarricenses". El banco se convirtió en un fin en sí mismo.

Las consecuencias de este proceso de transformación han sobre caído principalmente a los sectores agrícola, ganadero e industrial, siendo a su vez los sectores corporativos, quienes pueden sacar ventaja de las nuevas opciones financieras que ofrece la entidad, en especial los relacionados a inversiones en puestos de bolsa, banca de inversión, instrumentos financieros, etc., los más beneficiados, así como, los sectores vinculados a los mercados inmobiliarios, servicios y comercio. También, a través de Bicsa, el Banco Nacional buscó facilitar los negocios para los sectores vinculados a los mercados mundiales.

El BNcR logró incorporarse a los mercados financieros mundiales, de forma tal que participa del flujo económico mundial contribuyendo así al nuevo régimen de acumulación global que se expuso anteriormente.

El sistema financiero-bancario en el régimen de acumulación aperturista globalizado 
pone todas sus herramientas al servicio de la movilización de capitales nacionales y extranjeros para que sean invertidos en el lugar y momento que más ganancias generen a los capitalistas globales, facilitación de la apropiación privada de las ganancias de las inversiones, "profundización financiera" de la economía, financierización de las actividades productivas, sustentación del consumo vía el crédito $y$ reducción de la parte de la remuneración al trabajo en el reparto de las ganancias por el desarrollo del progreso técnico y el crecimiento en general, entre las principales. Costa Rica ha estado inmerso en ese proceso, lo que ha conllevado a que las características del nuevo régimen de acumulación y modo de regulación respondan en parte a la financierización, como se puede constatar en las trascendentes reformas que se han llevado adelante en el sistema financiero nacional desde la década de 1980.

\section{BIBLIOGRAFÍA}

LIBROS

Harvey, David. 2004. El nuevo imperialismo. España: Ediciones Akal.

Jessop, Bob. 1999. "Fordismo y Postfordismo: una reformulación crítica”. En Crisis del Estado de Bienestar: hacia una nueva teoría del Estado y sus consecuencias sociales, compilado por Bob Jessop, Alberto Supelano y Jorge Iván Bula. Colombia: Siglo del Hombre Editores.

Jessop, Bob y Ngai-Ling Sum. 2006. Beyond the regulation approach. Putting capitalist economies in their places. Inglaterra: Edward Elgar Publishing Limited.

Mandel, Ernest. 1969. Tratado de Economía Marxista. México: Ediciones Era sA.

Ministerio de Planificación Nacional y Política Económica de Costa Rica-mideplan. 1993. Ajuste estructural y sus efectos sobre el sector monetario-financiero. Costa Rica: MidePLAN.

Reuben, Sergio. 1988. Ajuste Estructural en Costa Rica: estudio socioeconómico de una década. Costa Rica: Editorial Porvenir.

Sevares, Julio. 2005. El imperio de las finanzas sobre las economías, las empresas y los ciudadanos. Buenos Aires: Grupo Editorial Norma.

\section{PUBLICACIONES PERIÓDICAS}

Bustelo, Pablo. 2003. "Enfoque de la regulación y economía política internacional ¿Paradigmas convergentes?”. Revista de Economía Mundial 8: 143-173.

Delgado, Edgar. 2001. "Banco Nacional desvelado por resultados". La Nación, 13 de agosto. Costa Rica. Acceso el 27 de agosto de 2014. http://wvw.nacion.com/ ln_ee/2001/agosto/13/economia1.html.

Reuben, Sergio. 2008. "La crisis económica actual, una vision desde la economía política". Revista de Ciencias Económicas 2, n. 20 : 71-103.

Reuben, Sergio. 2009. "Elementos para la comprensión de la crisis actual del capitalismo, una visión desde la periferia”. Reflexiones 1, n. ${ }^{\circ} 87$ : 137-153.

Volio, Alfredo. 2001. "La realidad del Banco Nacional". Semanario El Financiero, 1 de setiembre. Costa Rica. Acceso el 27 de agosto de 2014. http://wvw.elfinancierocr. com/ef_archivo/2001/septiembre/01/ opinion3.html.

TESIS

Cerdas, Daniel. 2013. "Modo de Regulación en la era de la financierización: El caso del Banco Nacional de Costa Rica, 19952005". Tesis de Maestría en Sociología. Universidad de Costa Rica

\section{TEXTOS ELECTRÓNICOS}

Harvey, David. 2005. "El 'nuevo imperialismo': acumulación por desposesión”. Buenos Aires: Consejo Latinoamericano de Ciencias Sociales-clacso. Acceso el 15 de abril de 2010. http://biblioteca.clacso.edu. $\mathrm{ar} / \mathrm{gsdl} / \mathrm{collect} / \mathrm{clacso} / \mathrm{index} / \mathrm{assoc} / \mathrm{D} 8555$. dir/harvey.pdf.

Harvey, David. 2007. "El neoliberalismo como destrucción creativa". Acceso el 13 de marzo de 2008. http://www.rebelion.org/ noticia.php?id=65709. 
OTROS

Banco Nacional de Costa Rica (BNcR). 1998. Plan estratégico 1999-2003. Costa Rica: BNcR.

Banco Nacional de Costa Rica (BNCR). 1999. Memoria Institucional 1998. Costa Rica: BNCR.

Banco Nacional de Costa Rica (BNCR). 2000. Memoria Institucional 1999. Costa Rica: BNCR.

Banco Nacional de Costa Rica (BNCR). 2001. Memoria Institucional 2000. Costa Rica: BNCR.
Hayden, William. s. f. Transformación de un banco ruinoso a un banco exitoso: Memorias de mis doce años en la gerencia del Banco Nacional de Costa Rica. Documento Inédito.

Fecha de ingreso: 30/08/2014 Fecha de aprobación: 06/03/2015 